\title{
Kazı Derinliğinin Püskürtme Beton Dayanımı Üzerindeki Etkisi: Sayısal Bir Yaklaşım
}

\author{
Effect of Excavation Depth on Shotcrete Strength: A Numerical Approach
}

\author{
Mustafa KANIK*a Zülfü GÜROCAK ${ }^{\mathrm{b}}$ \\ Fırat Üniversitesi Mühendislik Fakültesi, Jeoloji Mühendisliği Bölümü, 23119, Elazı̆̆
}

\begin{tabular}{llll}
\hline •Geliş tarihi / Received: $17.08 .2017 \quad$ •Düzeltilerek geliş tarihi / Received in revised form: 27.10.2017 • Kabul tarihi / Accepted: 30.10 .2017 \\
\hline
\end{tabular}

\begin{abstract}
$\ddot{O} z$
Uygun ve güvenilir destek sistemlerinin seçimi, tünelcilikte maliyet ve güvenliği etkileyen en önemli faktörlerden birisidir. Farklı araştırmacılar tarafindan önerilmiş olan görgül kaya sınıflama yöntemleri destek tipinin seçiminde büyük kolaylık sağlamaktadır. Bu konuda kullanılan diğer bir yöntem sayısal analizlerdir. Görgül olarak elde edilen destek tipinin sayısal olarak da analiz edilmesi sonucunda daha güvenilir ve ekonomik destek tipi belirlenebilmektedir. $\mathrm{Bu}$ çalışmada, farklı kaya sınıfları için $\mathrm{RMR}_{89}$ tarafından önerilen püskürtme betonun dayanımı ile kazı derinliği arasındaki ilişkileri incelemek amacıyla Sonlu Elemanlar Yöntemi (FEM) kullanılarak sayısal modellemeler yapılmıştır. Modellemelerde, Zayıf, Orta ve İyi kaliteli kaya sınıfındaki kaya kütleleri ve farklı kazı derinlikleri dikkate alınmıştır. Kazı derinliğinin artması bağlı olarak, destek sisteminin yenilmeden çalışabilmesi için püskürtme beton dayanımının ne kadar olması gerektiği araştııılmışıı. Yapılan analizlere göre püskürtme beton dayanımının $30 \mathrm{MPa}$ alınması durumda, İyi kaliteli Kaya sınıfında 450 m, Orta kaliteli Kaya sınıfında 310 m, Zayıf kaliteli Kaya sınıfinda ise 200 m kazı derinliğinde püskürtme betonda yenilmeler meydana gelmektedir. Bu derinliklerden sonra destek sisteminin duraylı kalabilmesi için püskürtme beton dayanımının artırılması gerekmektedir. Püskürtme beton dayanımı $40 \mathrm{MPa}$ 'ya çıkarıldığında, İyi kaliteli Kaya sınıfında 530 m, Orta kaliteli Kaya sınıfında 420 m ve Zayıf kaliteli Kaya sınıfında ise $260 \mathrm{~m}$ kazı derinliğine kadar destek elemanlarında yenilme meydana gelmemektedir. İyi kaliteli kaya sınıfında $20 \mathrm{MPa}$ dayanımlı püskürtme beton için yapılan analizlerde, $410 \mathrm{~m}$ örtü kalınlığına kadar destek sisteminde yenilme meydana gelmemektedir. Bu çalışmadan elde edilen sonuçlar, kazı derinliğinin artması sonucunda, destek sistemlerinin yenilmemesi için püskürtme beton dayanımın artıılması veya bir alt kaya sınıfı için önerilen destek sistemlerinin seçilmesi gerektiğini göstermektedir.
\end{abstract}

Anahtar kelimeler: Kazı derinliği, Püskürtme beton dayanımı, RMR sınıflama sistemi, FEM analizi

\begin{abstract}
Choosing appropriate and reliable support systems is one of the most important factors affecting cost and security in tunneling. The empirical rock classification methods proposed by different researchers provide great convenience in selecting the support type. Another method used in this regard is numerical analysis. With the aid of the numerical analyses, analyzing the support system empirically obtained helps to determine more reliable and economic support types. In this study, numerical models were developed using Finite Elements Method (FEM) to investigate the relationship between the strength of shotcrete and the excavation depth for the different rock classes proposed by $R M R_{89}$. Different excavation depths for Weak, Fair and Good rock masses are taken into account in the modeling. Depending on the increase in depth of excavation, it has been researched how much the strength of the shotcrete must be so that the support system can continue to support without being yielded. According to the evaluated models, when the shotcrete strength is assumed as $30 \mathrm{MPa}$, the elements of shotcrete was started to yielded at $200 \mathrm{~m}$ depth for the weak rock mass, $310 \mathrm{~m}$ depth for the fair rock mass and $450 \mathrm{~m}$ depth for the good rock mass. After reaching the mentioned depths, it is necessary to increase the strength of the shotcrete in order to keep the support system stable. Once the shotcrete strength is increased to $40 \mathrm{MPa}$, there was not failure in the support elements up to the excavation depth of $530 \mathrm{~m}$ in the good rock mass, $420 \mathrm{~m}$ for fair rock mass and $260 \mathrm{~m}$ for the weak rock mass. The support system was determined stable up to 410 m overburden in the evaluated analyses for 20 MPa strengthen shotcrete. In this study, it is revealed that, the increase in depth of excavation indicates that the strength of the shotcrete must be increased to avoid instabilities of the support systems or that the support systems recommended for a lower rock class should be selected.
\end{abstract}

Keywords: Excavation depth, Numerical modeling, RMR classification system, Shotcrete strength

*a Zülfü GÜROCAK; zgurocak@ gmail.com; Tel: (0532) 35536 47; orcid.org/0000-0002-1049-8346

${ }^{b}$ orcid.org/0000-0002-1019-5249 


\section{Giriş}

Tünelcilikte maliyet üzerindeki en önemli parametrelerden birisi, tünelde kullanılacak olan destek sistemlerinin çeşididir. Bu parametre kazı sırasında geçilecek birimlerin jeolojik ve jeoteknik özellikleri ile doğrudan ilişkilidir. Tünel güzergâhındaki birimlerin jeolojik ve jeoteknik özelliklerinin belirlenebilmesi ise tünel güzergâhı boyunca sondaj ve yüzey çalışmalar ile mümkündür. Tünelcilikte ön destek sistemlerinin saptanması amacıyla farklı araştırmacılar tarafından birçok kaya kütle sınıflama sistemi önerilmiştir (Terzaghi, 1946; Lauffer, 1958; Deere, 1964; Wickhamvd., 1972; Bieniawski, 1989; Barton vd., 1974; Palmström, 1995). Önerilen bu sistemler zaman zaman revize edilerek günümüzdeki halini almıştır.

Terzaghi (1946) tarafından önerilen sınıflama sistemi 35 yıldan fazla bir süre etkili olarak kullanılmıştır. Lauffer (1958) ise, Stini (1950) tarafindan yapılan bir çalışmadan esinlenerek, destek sisteminin çeşidi ve miktarını tünel genişliği ve desteksiz durma süresine bağlı olarak belirlemeye çalışmıştır. Deere (1964) sondaj karotlarından belirlenebilen Kaya Kalite Göstergesi (RQD) parametresini kullanarak bir sınıflama önermiştir. Wickham vd. (1972) tarafından Amerika Birleşik Devletleri'nde geliştirilen kaya yapısı değerlendirmesi (RSR) kavramı, sınıflandırma parametrelerinin nispi önemini ölçmek için yapılan ilk sınıflandırma sistemdir. Bieniawski (1989) tarafından önerilen Kaya Kütle Puanlama (RMR) ve Barton vd. (1974) tarafindan önerilen Kaya Kütle Kalitesi (Q) sistemleri birbirlerinden bağımsız olarak geliştirilmişlerdir.

Bu sinıflama sistemlerinin ikisi de kaya bulonu ve püskürtme beton gibi modern tünel güçlendirme yöntemlerinin seçimini sağlayacak niceliksel veriler sağlamaktadırlar. Kaya Kütle İndeksi (RMi) sinıflama sistemi Palmström tarafindan 1995 y1lında, Jeolojik Dayanım İndeksi (GSI) ise ilk defa Hoek vd. (1995) tarafından önerilmiştir. Q, RMR, RMi ve GSI sistemleri zaman içinde revize edilerek günümüzdeki şeklini almışlardır.

Ayrica, destek tipinin kazı sirasinda belirlenmesinde Yeni Avusturya Tünel Açma Yöntemi (NATM) sistemi de yaygın olarak kullanılmaktadır. Bu metotta diğer sistemler gibi kesin önerilmiş destek elemanları yerine kullanılması gereken destek elemanlarının türü belirtilmiş olup, destek elemanı sistematiği uygulayıc1lar tarafindan belirlenmektedir.

\section{Tünelcilikte Destek Sistemlerinin Görgül Olarak Belirlenmesi}

Tünelcilikte ön destek sistemlerinin belirlenmesinde temeli puanlama metoduna dayanan RMR, Q ve RMi sistemleri yaygın olarak kullanılmaktadır. Bu sinıflamalarda puanlamalar genel olarak kaya malzemesinin mekanik özellikleri, süreksizliklerin özellikleri ve su durumuna göre yapılmakta ve elde edilen sonuca göre ön destek sistemi belirlenmektedir. Yaygin olarak kullanılan bu sistemlerinin avantajları yanında dezavantajları da vardır.

$\mathrm{Bu}$ görgül sinıflama sistemlerinin avantajları maddeler halinde siralanacak olursa:

- Kaya kütleleri sınıflandırılırken, girilen veriler sistematik olarak tanımlandığından saha araştırmalarının kalitesi daha da artmaktadır.

- $\mathrm{Bu}$ siniflamalarda nicel bir değerlendirme yapıldığından kişisel değerlendirmelere kıyasla daha güvenilir sonuçlar elde edilmektedir.

- Sinıflandırma, her kaya kütlesinin kilit parametreleri için bir kontrol listesi oluşturmaktadır. Diğer bir deyişle, kaya kütlesinin tanımlanması sürecini yönlendirmektedir.

- Sinıflandırma, tasarım amaçlı nicel bilgilerle sonuçlanmakta ve bir proje üzerinde daha iyi mühendislik kararı ve etkili iletişim imkânı sağlamaktadır (Bieniawski, 1993).

- Nicel bir sinıflandırma, belirli bir projede sağlıklı mühendislik yargısı için uygun ve etkili iletişim sağlamaya yardımcı olmaktadır (Hoek, 2007).

- Kaya kütlesinin kalitesi ve mekanik özellikleri arasındaki ilişkiler kaya kütlesinin deformasyon, dayanım veya şişme özelliklerini belirlemek ve tahmin etmek için de kullanılabilmektedir.

Dezavantajları bakımından ele alındığında;

- Tek bir siniflama sisteminden elde edilen sonuçların diğer sistemler ile karşılaştırmadan kullanılmas1, analitik ve gözlemsel tasarım metotlarını göz ardı etmekte ve projedeki olası duraylılık problemlerini önleyememektir.

- Kaya kütlesi siniflama sistemlerinin, üzerinde geliştirildikleri veri tabanından kaynaklanan sınırlamaların tam olarak anlaşılmadan kullanılmas1 durumunda güvenilir sonuçlar elde edilememektedir (Bieniawski, 1993).

- Elde edilen sonuçlarının yanlış değerlendirilmesi veya kullanılması gerçekçi 
olmayan destek seçiminin yapılmasına neden olabilmektedir.

- Sinıflandirma sistemlerinin yardımıyla belirlenen destek sisteminin gerçekçiliğinin, uygulamaya geçilmeden önce test edilememesi zorluklara veya duraylilik problemlerine yol açabilmektedir.

- Kaya kütle sinıflama sistemleri tarafindan önerilen destek elemanlarına (püskürtme beton, kaya bulonu, vb) ait teknik özelliklerin (püskürtme beton dayanımı, kaya bulonu çapı ve dayanımı) tanımlanmamış olması nedeniyle tasarım sırasında güçlüklerle karşılaşılabilmektedir.

Ön destek tasarımın uygulama aşamasındaki güvenirliliği, son yıllarda sıklıkla kullanılan sayısal analizler yardımıyla test edilmektedir. Bu konuda yapılan çalışmalarda (Geniş vd., 2007; Gürocak vd., 2007; Gürocak, 2011; Kaya vd., 2011; Kaya ve Bulut, 2013, Kanık vd., 2015; Yalçın vd., 2016, Kaya ve Sayın, 2017) RMR, Q ve RMi gibi görgül sinıflamalar ve sayısal analizler birlikte kullanılmış ve destek tasarımında ampirik ve sayısal yöntemlerin bütünleştirilmesinin önemi ortaya konulmaya çalışılmıştır. Görgül olarak belirlenen ön destek sistemlerinin güvenirliliğinin sayısal yöntemler ile analiz edilmesi, daha gerçekçi destek sistemlerinin belirlenebilmesine imkân tanımaktadır.

$\mathrm{Bu}$ çalışmanın amacı, görgül sistemler tarafından önerilen püskürtme beton dayanımının derinlikle olan ilişkisini ortaya koymaktır. Nitekim görgül sistemler destek sistemi olarak püskürtme betonu önermekte ancak uygulanacak püskürtme betonun dayanımı hakkında herhangi bir öneride bulunmamaktadır. $\mathrm{Bu}$ nedenle, uygulama sirasında genellikle $30 \mathrm{MPa}$ dayanıma sahip püskürtme beton kullanılmaktadır. Ancak, duraylılığı sağlamak amaciyla artan kazı derinliği ile birlikte püskürtme beton dayanımının da artırılması gerekliliği düşünüldügünde, kazı derinliği ile püskürtme beton dayanımı arasındaki ilişkinin önemli olduğunu söylemek mümkündür.

Günümüze kadar püskürtme beton tasarımı konusunda farklı araştırmacılar tarafından yapılmış bir çok çalışma bulunmaktadır (Wood vd., 1993; Kirsten, 1992; Beauprè vd., 2005; Badr ve Brooks, 2008; Patel vd., 2012; Barros vd., 2014; NIOSH, 2014; Zhang, 2014; Mohajerani vd., 2015; Badr, 2016). Bu çalışmalar genel olarak püskürtme betonun tasarımı ve dayanımının artırılması konusundadır. Artan kazı derinliği ile püskürtme betonun dayanımının ne kadar olması gerektiği konusunda yapılmış herhangi bir çalışma bulunmamaktadır.

Bu çalışmada, kazı derinliğinin püskürtme beton dayanımı üzerindeki etkisini incelemek amacıyla sayısal analizlerden yararlanılmış ve bu etki ortaya çıkarılmaya çalışılmıştır. Bu amaçla, en yaygın olarak kullanılan görgül yöntemlerden birisi olan $\mathrm{RMR}_{89}$ sistemine ait kaya sinıfları dikkate alınmıştır.

Görgül bir kaya kütle sinıflama sistemi olan RMR Sınıflama Sistemi, ilk kez 1972-1973 yılları arasında yapılan çalışmalar sonucunda Bieniawski (1973) tarafından geliştirilmiştir. Sınıflamaya ait parametreler ve bu parametrelere ait puanlarm belirlenmesi konusunda yine Bieniawski tarafindan 1989 yılında yapilan öneriler ile modifiye edilen RMR siniflamas1 $\left(\mathrm{RMR}_{89}\right)$, son olarak 2014 yılında yapılan değişiklikler (Celada vd., 2014) ile son halini almıştır. Yaygın olarak kullanılması ve kabul edilmiş olması sebebiyle bu çalışmada RMR sisteminin 1989 versiyonu tercih edilmiştir.

$\mathrm{RMR}_{14}$ 'ün önerilmesinden önce uzunca bir süre kullanılan $\mathrm{RMR}_{89}$ sistemi aşağıdaki girdi parametrelerini kullanmaktadır;

- Kayacın tek eksenli basınç dayanımı veya nokta yükü dayanım indeksi,

- Kaya kalitesi göstergesi (\% RQD)

- Süreksizlik ara uzaklığ

- Süreksizliklerin durumu (devamlılık, açıklık, pürüzlülük, dolgu ve bozunma)

- Yeraltı suyu durumu

$\mathrm{RMR}_{73}$ versiyonunda dayanım, RQD ve süreksizlik ara uzaklığı için yapılan değerlendirmeler aralıkların sınır değerlerini de kapsamaktayd 1 ve bu durum uygulamada hatalara sebep olmaktayd. Bu üç parametrenin daha hassas puanlanabilmesi için Bieniawski (1989), ISRM (1981) tarafindan önerilen tanımlama ölçütlerini esas alınarak çeşitli abaklar geliştirilmiştir.

RMR $_{89}$ 'a göre kaya kütlesinin temel RMR puanı belirlendikten sonra süreksizlik düzeltmeleri yapılıp nihai RMR puanı elde edilmektedir. Daha sonra düzeltilmiş RMR puanı ile kaya sınıfi ve ön destek önerileri Tablo 1'den belirlenmektedir.

\section{Sayısal Modellemeler}

$\mathrm{Bu}$ çalışmada, analiz modelleri oluşturulurken Sonlu Elemanlar Yönteminden (FEM) yararlanılmıştır. 
Tablo 1. RMR ${ }_{89}$ sistemine göre kaya kütle sınıfları için önerilen birincil destekler (Bieniawski, 1989).

\begin{tabular}{|c|c|c|c|c|}
\hline \multicolumn{5}{|c|}{ BİRİNCILL DESTEK } \\
\hline $\begin{array}{l}\text { Kaya } \\
\text { Kütle } \\
\text { Sinıfi }\end{array}$ & Kazı & $\begin{array}{l}\text { Kaya sapmaları * }(10 \mathrm{~m} \\
\text { genişlikteki tünel için uzunluk })\end{array}$ & Püskürtme beton & Çelik destek \\
\hline $\mathrm{I}$ & Tam kesit, $3 \mathrm{~m}$ ilerleme. & \multicolumn{3}{|c|}{ Bir miktar kaya saplaması haricinde genellikle destek gerektirmez. } \\
\hline II & $\begin{array}{l}\text { Tam kesit, } 1.0-1.5 \mathrm{~m} \text { ilerleme, tam kazı } \\
\text { destek. Aynaya } 20 \mathrm{~m} \text { mesafede }\end{array}$ & $\begin{array}{l}\text { Kemerin her } 2-3 \mathrm{~m} \text { ' sinde yer yer } \\
\text { saplama, tel kafeslerle } 2-2.5 \mathrm{~m} \\
\text { aralıkl1. }\end{array}$ & $\begin{array}{l}\text { Gerektiğinde tavan } \\
\text { kemerinde } 50 \mathrm{~mm} \text {. }\end{array}$ & Gerekmez \\
\hline III & $\begin{array}{l}\text { Tavan kemeri ve tabandan ilerleme. } \\
\text { Tavandan } 1.5-3 \mathrm{~m} \text { ilerleme. Tam kazı } \\
\text { destek. Aynaya } 10 \mathrm{~m} \text { mesafeye kadar } \\
\text { gerekli. }\end{array}$ & $\begin{array}{l}\text { 3-4 m uzunlukta } \text { sistematik } \\
\text { saplamalar, kemerde tel kafesli } \\
\text { duvarlar ve kemerde } 1.5-2 \mathrm{~m} \\
\text { aralıklı. }\end{array}$ & $\begin{array}{ll}\text { Tavan kemerinde } & 50- \\
100 \mathrm{~mm} \text { ve } & \text { yan } \\
\text { duvarlarda } 30 \mathrm{~mm} . & \end{array}$ & Gerekmez \\
\hline IV & $\begin{array}{l}\text { Tavan kemeri ve tabandan ilerleme. } \\
\text { Tavandan } 1.0-1.5 \mathrm{~m} \text { ilerleme. Kazlya } \\
\text { uygun şekilde aynaya } 10 \mathrm{~m} \text { mesafeye } \\
\text { kadar, gerekli destek. }\end{array}$ & $\begin{array}{l}\text { Tel kafesli duvarlarda ve } \\
\text { kemerde } 1-1.5 \mathrm{~m} \text { aralıklı, } 4-5 \mathrm{~m} \\
\text { uzunlukta sistematik saplama. }\end{array}$ & $\begin{array}{l}\text { Tavan kemerinde } 100- \\
150 \mathrm{~mm} \text { ve yan } \\
\text { duvarlarda } 100 \mathrm{~mm} .\end{array}$ & $\begin{array}{l}\text { Gereken yerde } 1.5 \\
\mathrm{~m} \text { aralıklı yer yer } \\
\text { hafif traversler. }\end{array}$ \\
\hline $\mathrm{V}$ & $\begin{array}{l}\text { Tavan ve tabanda birlikte ilerleme. } \\
\text { Tavandan } 0.5-1 \mathrm{~m} \text { ilerleme, kaziyla } \\
\text { birlikte destek yerleştirilmeli. Patlamadan } \\
\text { hemen sonra püskürtme beton } \\
\text { uygulanmalı. }\end{array}$ & $\begin{array}{l}\text { Tel kafesli duvarlarda ve } \\
\text { kemerde } 1-1.5 \mathrm{~m} \text { aralıkl1, } 5 \mathrm{~m} \\
\text { uzunlukta sistematik saplama. }\end{array}$ & $\begin{array}{l}\text { Tavan kemerinde } 150- \\
200 \mathrm{~mm} \text {, yan duvarlarda } \\
150 \mathrm{~mm} \text {, aynada } 50 \\
\mathrm{~mm} .\end{array}$ & $\begin{array}{l}\text { Çelik iksalı, } 0.75 \\
\text { m aralıklı orta-ağır } \\
\text { traversler. }\end{array}$ \\
\hline
\end{tabular}

$\mathrm{Bu}$ yöntemin temeli, karmaşı bir problemi basit ve küçük parçalara bölerek çözme esasına dayanmaktadır. Böylece, kesin sonuçtan ziyade yaklaşık bir sonuç elde edilebilmekte ve elde edilen yaklaşık sonucun üzerinde çalışarak kesin bir sonuç elde etmek mümkün olmaktadır. Rocscience (2011) tarafından geliştirilmiş olan Phase $^{2}$ v8.0 (Plastic Hybrid Analysis of Stress for Estimation of Support) bilgisayar programı kullanılarak geliştirilen modellemelerde 6 düğümlü üçgen sonlu elemanlar kullanılmış ve tünelin 5 katı genişliğinde bir kaya ortamı oluşturulmuştur. Modellemeler, $10 \mathrm{~m}$ genişliğinde, 7 metre yüksekliğinde, tek tüp, at nalı kesitindeki zayıf, orta ve iyi kaliteli kaya sınıfındaki kaya kütleleri için $\mathrm{RMR}_{89}$ sisteminin önerdiği ön destek sistemleri için farkl1 derinliklerde yapılmıştır (Şekil 1).

Buradaki amaç, kazıdan sonra uygulanan püskürtme betonun yenilmeden işlevini sürdürebilmesi için değişen derinliklerde hangi dayanıma sahip olması gerektiğinin belirlenebilmesidir. Analizlerde, maksimum toplam yer değiştirme $\left(\mathrm{U}_{\mathrm{t}}\right)$ ve plastik zon kalınlığındaki $\left(\mathrm{T}_{\mathrm{pl}}\right)$ değişimler dikkate alınmış ve $10 \mathrm{~m}$ örtü kalınlığından başlayıp farklı kaya sınıfları için $550 \mathrm{~m}$ derinliğe kadar yapılmıştır. Her bir derinlikte zayıf ve orta kaliteli kayalar için beton dayanımının hem $30 \mathrm{MPa}$ hem de $40 \mathrm{MPa}$ olduğu, iyi kaya için ise beton dayanımının 20 $\mathrm{MPa}, 30 \mathrm{MPa}$ ve $40 \mathrm{MPa}$ olduğu durumlara göre sayısal analizler yapılmıştır. Sayısal analizlerde, derinlik arttıkça zayıf ve orta kayada püskürtme beton dayanımının yetersiz kalma olasılığının yüksek olmasından dolayı duraysızlık durumunda beton dayanımı $40 \mathrm{MPa}$ ya yükseltilerek yeni analizler yapılmıştır. $30 \mathrm{MPa}$ 'lık püskürtme beton dayanımının iyi kaya için belli bir derinliğe kadar gereğinden yükssek olabilmesi olasıllı̆ından dolayı $20 \mathrm{MPa}$ dayanımlı püskürtme beton kullanılarak analizler yapılmıştır. $30 \mathrm{MPa}$ dayanıma sahip püskürtme betonun referans değer olarak alınmasının sebebi ise, bu değerin yapılan çalışmalar (Celada vd., 2014) ve teknik şartnamelerde (KGM, 1997) istenen püskürtme beton dayanımı olarak kabul edilmesidir.

\subsection{Farklı Kaya Sınıfları ve Derinlikler için Yapılan Sayısal Modellemeler}

Modellemeler yapılırken, kaya türü olarak magmatik kaya ve $\mathrm{RMR}_{89}$ sistemine göre zayıf (IV), orta (III) ve iyi (II) kaya sinıfina ait kaya kütleleri seçilmiştir. Sadece Zayıf, Orta ve İyi kaliteli kaya sınıflarının seçilmesinin sebebi, Çok İyi kaliteli kaya kütlelerinde püskürtme betonun destekten ziyade emniyet için kullanılması, Çok Zayıf kaliteli kaya kütlelerinde ise çelik iksa desteğinin ön planda olmasi ve püskürtme betonun ikinci planda kaldığının düşünülmesidir.

Sayısal analizlerde girdi parametresi olarak kullanılacak veriler ise fay ve kıvrım içermeyen (fay ve kıvrımlanma olan bölgelerdeki değişken gerilme dağılımlarını göz ardı etmek amaciyla), bloklu ve çok bloklu kayaların Hoek-Brown sabitleri, GSI değerleri, Poisson oranları, kaya malzemesinin ve kaya kütlesinin deformasyon modülleri Hoek vd. (1995) tarafindan verilen ve RocLab (Rocscience, 2006) programı yardımıyla hesaplanan değerler kullanılarak belirlenmiştir. Birim hacim ağırlıklar $(\gamma)$ her bir kaya kütlesi için $26 \mathrm{kN} / \mathrm{m}^{3}$, tek eksenli sıkışma dayanımı değeri $\left(\sigma_{c}\right)$ ise her bir kaya sınıfı için ortalama değerler olarak kabul edilmiştir. 


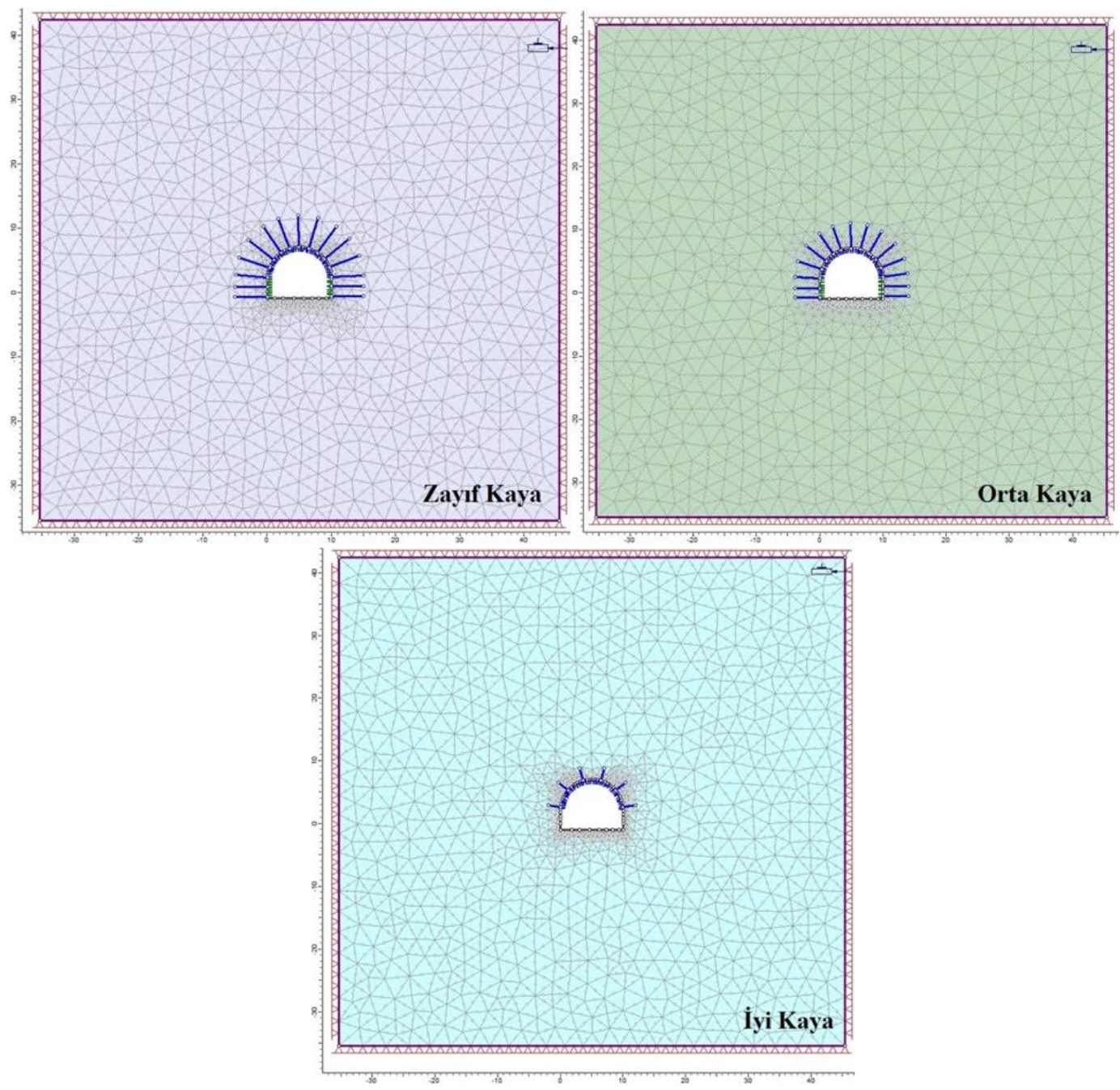

Şekil 1. Zayıf, Orta ve İyi kalitedeki kaya kütleleri için oluşturulan modeller.

GSI, $\mathrm{m}_{\mathrm{b}}$, s, a için artık değerler Cai vd. (2007) tarafindan önerilen eşitlikler ile belirlenmiştir.

$\mathrm{GSI}_{\mathrm{r}}=$ GSI.e $\mathrm{e}^{-0.0134 \mathrm{GSI}}$

$\mathrm{m}_{\mathrm{br}}=\mathrm{m}_{\mathrm{i}} \cdot \mathrm{e}^{\left(\frac{\mathrm{GSSI}-100}{28}\right)}$

$\mathrm{S}_{\mathrm{r}}=\mathrm{e}^{\left(\frac{\mathrm{GSIr}-100}{9}\right)}$

$a_{r}=\frac{1}{2}+\frac{1}{6}\left(e^{-G S I r / 15}-e^{-20 / 3}\right)$

Tüm kaya kütle özellikleri ve sayısal analizlerde kullanılan girdi parametreleri ve bu parametrelere ait değerler Tablo 2'de verilmiştir. Ayrıca, kullanılan destek elemanlarının teknik özellikleri de Tablo 3' de sunulmuştur.

Tünel kazı kotundaki düşey $\left(\sigma_{\mathrm{v}}\right)$ ve yatay $\left(\sigma_{\mathrm{h}}\right)$, gerilmeler, her derinlik için ayrı olarak hesaplanmıştır. Düşey gerilme $\left(\sigma_{v}\right)$ değerleri, Fenner (1938) tarafından önerilen eşitlik kullanılarak hesaplanmıștır. $\sigma_{\mathrm{v}}=\gamma \cdot \mathrm{H}$

Bu eșitlikte;

$\gamma$ : Birim hacim ağırlık $\left(\mathrm{kN} / \mathrm{m}^{3}\right)$,

H: Örtü kalınlığ 1 (m) dır.

Yatay gerilme $\left(\sigma_{\mathrm{h}}\right)$ ise çok değişken ve belirlenmesi zor olan bir parametredir. Yatay gerilmeyi belirleyebilmek için Sheorey vd. (2001) tarafından önerilen eşitlikten yararlanılmıştır.

$\sigma_{\mathrm{h}}=\frac{v}{1-\mathrm{v}} \sigma_{\mathrm{v}}+\frac{\beta \mathrm{E}_{\mathrm{m}} \mathrm{G}}{1-v}(\mathrm{H}+1000)$

Bu eşitlikte;

$\beta$ : Doğrusal termal genleşme katsayısı ( $8 \times 10^{-}$ $\left.{ }^{6} /{ }^{\circ} \mathrm{C}\right)$,

G: Jeotermal gradyan $\left(0.024{ }^{\circ} \mathrm{C} / \mathrm{m}\right)$,

v: Poisson oran1,

H: Örtü Kalınlığ 1 (m)

$\mathrm{E}_{\mathrm{m}}$ : Kaya kütlesinin deformasyon modülü $(\mathrm{GPa})$.

İlk aşamada, sayısal analizler Zayıf, Orta ve İyi kaliteli kaya sınıfları için desteksiz duruma 
göreyapılmıştır. Daha sonra $\mathrm{RMR}_{89}$ tarafından önerilen ve Tablo 1'de verilen destek sistemleri seçilmiş ve her $10 \mathrm{~m}$ 'de bir sayısal analizler yapılmıştır. Ancak, sayısal analizlerde, belli bir derinlikten sonra birbirlerine yakın değerler elde edildiğinden dolayı $10 \mathrm{~m}$ örtü kalınlığından başlayıp sırasıyla $50 \mathrm{~m}$ ve katlarına karşılık gelen derinlikler için yapılmıştır.

Tablo 2. Sayısal analizlerde kullanılan girdi parametreleri

\begin{tabular}{llll}
\hline & Zaylf Kaya & Orta Kaya & İyi Kaya \\
\hline$\sigma_{\mathrm{v}}, \mathrm{MPa}$ & $0.26-13.78$ & $0.26-11.7$ & $0.26-11.7$ \\
$\sigma_{\mathrm{h}}, \mathrm{MPa}$ & $0.08-3.89$ & $0.1-4.55$ & $0.09-3.91$ \\
$\sigma_{\mathrm{ci}}, \mathrm{MPa}$ & 30 & 75 & 150 \\
$\mathrm{E}_{\mathrm{i}}, \mathrm{GPa}$ & 12000 & 27500 & 55000 \\
$v$ & 0.28 & 0.25 & 0.22 \\
$\gamma, \mathrm{kN} / \mathrm{m}^{3}$ & 26 & 26 & 26 \\
$\mathrm{E}_{\mathrm{m}}, \mathrm{GPa}$ & 7000 & 14000 & 32000 \\
$\mathrm{GSI}$ & 43 & 55 & 70 \\
$\mathrm{~m}_{\mathrm{i}}$ & 18 & 20 & 25 \\
$\mathrm{~m}_{\mathrm{b}}$ & 2.351 & 4.009 & 8.563 \\
$\mathrm{~m}_{\mathrm{br}}$ & 1.199 & 1.439 & 1.8701 \\
$\mathrm{~s}$ & 0.0018 & 0.0067 & 0.0357 \\
$\mathrm{~s}_{\mathrm{r}}$ & 0.00022 & 0.00028 & 0.00031 \\
$\mathrm{a}$ & 0.509 & 0.504 & 0.501 \\
$\mathrm{a}_{\mathrm{r}}$ & 0.533 & 0.529 & 0.527 \\
\hline
\end{tabular}

Yapılan sayısal analizlerin sonuçlarına göre, püskürtme beton dayanımı $30 \mathrm{MPa}$ olarak alındığında Zayıf kaliteli kaya sınıfı için 200 m'den sonra püskürtme betonda yenilmeler ortaya çıkmaktadır (Şekil 2, Tablo 4). Orta kaliteli kaya sınıfı için ise $30 \mathrm{MPa}$ dayanımlı püskürtme betonlu destek sistemi $310 \mathrm{~m}$ derinlikte, İyi kaya sinıfinda ise $450 \mathrm{~m}$ derinlikte yenilmeye başlamıştır(Şekil 2, Tablo 5 ve 6).

Zayıf kaliteli kaya sınıfında püskürtme beton dayanımının $40 \mathrm{MPa}$ olarak alınması durumunda, püskürtme betondaki yenilmeler 260 m'den itibaren başlamaktadır. Orta kaliteli kaya sınıfında püskürtme betondaki yenilmeler 420 m'den sonra, iyi kaliteli kaya sinıfinda ise 530 m'den sonra başlamaktadır (Şekil 3, Tablo 4, 5 ve 6).

Püskürtme betonda meydana gelen yenilmeler kırmızı renk ile gösterilmiş olan bölgelerde meydana gelmektedir. Yenilen bölgelerde çelik hasırların güvenlik katsayılarının destek kapasite diyagramlarında 1 in üstünde olması, yenilmelerin püskürtme beton dayanımının yetersizliğinden kaynaklandığını göstermektedir (Şekil 2 ve 3). Destek kapasite diyagramlarında daire içine alınmış olan destek elemanları, tünel kesitinde daire içine alınmış yenilen püskürtme betonla birlikte hareket eden çelik hasırı temsil etmektedir.

Ayrıca İyi kaliteli kaya sınıfında sı $\breve{g}$ derinliklerde $30 \mathrm{MPa}$ püskürtme beton dayanımının fazla olabileceği düşünülerek $20 \mathrm{MPa}$ dayanımlı püskürtme beton için de sayısal analizler yapılmış ve sonuç olarak püskürtme betondaki yenilmelerin 410 m'den sonra başladığı görülmüştür (Şekil 4). Tablo 7'de verilen değerlere bakıldığında, gerek plastik zon kalınlıkları gerekse toplam yer değiştirme değerlerinde yenilme olan derinliğe kadar bir farklılık olmadığı görülmektedir. Dolayısıyla, İyi kaliteli kaya sınıfi için yaklaşık 410 metre derinliğe kadar $20 \mathrm{MPa}$ 'lık püskürtme beton dayanımı yeterli olmaktadır.

Tablo 3. Sayısal analizlerde kullanılan destek elemanlarının karakteristik özellikleri

\begin{tabular}{lccc}
\hline Özellikler & Püskürtme beton & Kaya bulonu & Çelik hasır \\
\hline Elastisite modülü, (GPa) & 30 & 200 & 200 \\
Poisson oranı, & 0.2 & - & 0.35 \\
Tek eksenli basınç dayanımı, (MPa) & 30 & - & 500 \\
Artık tek eksenli basıç dayanımı, (MPa) & 3.0 & - & - \\
Çekme dayanımı, (MPa) & - & - & 500 \\
Artık dayanımı, (MPa) & - & - & - \\
Çekme kapasitesi (MN) & - & 0.2 & - \\
Artık Çekme kapasitesi (MN) & - & 0.02 & - \\
Tür & - & $\emptyset 20 \mathrm{~mm} \mathrm{SN}$ & $\varnothing 6.5 / 150 \times 150 \mathrm{~mm}$ \\
\hline
\end{tabular}



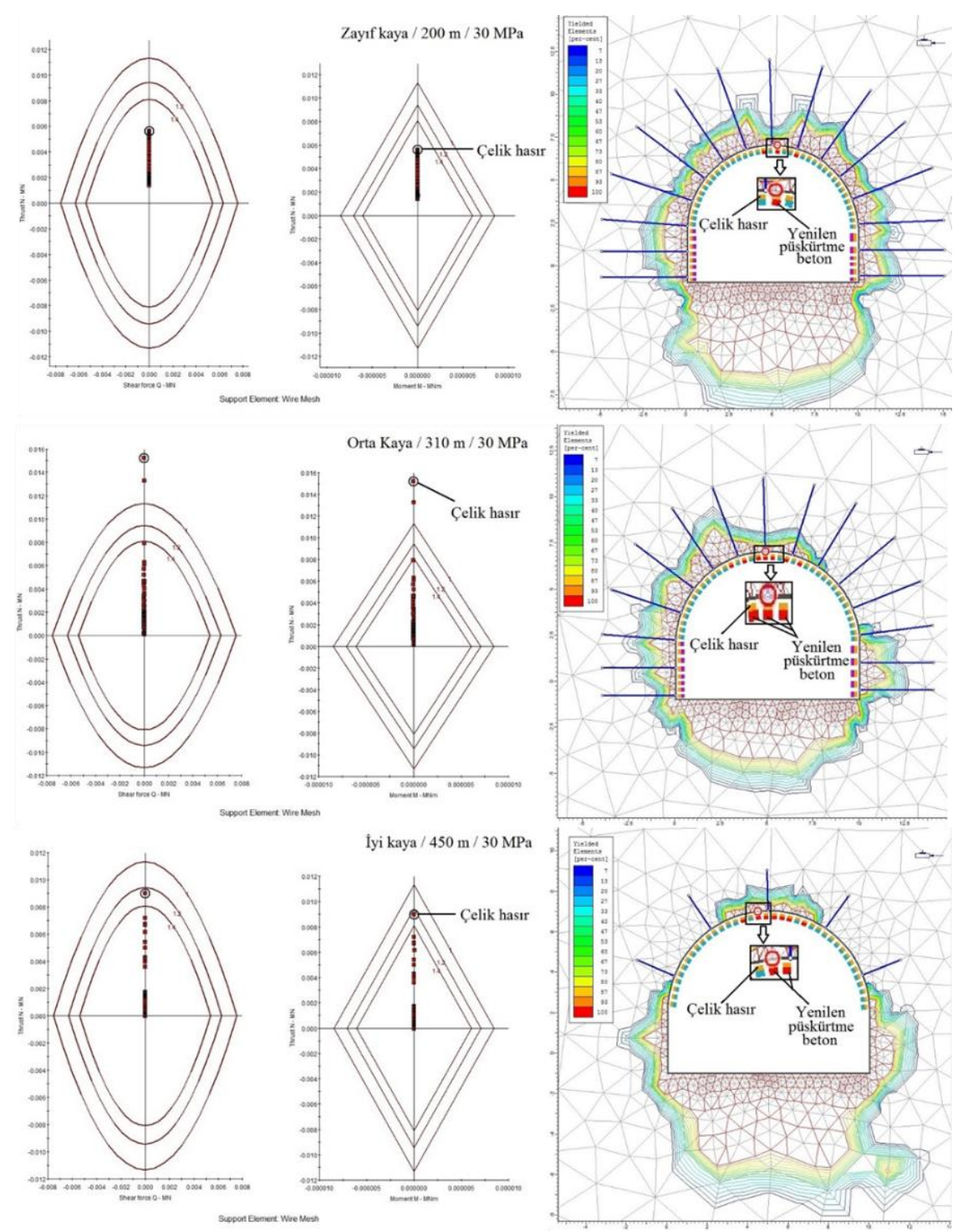

Şekil 2. $30 \mathrm{MPa}$ 'lık püskürtme betonda çelik hasır destek kapasitesi grafikleri ve plastik zon yayılımı (1-1.2-1.4 güvenlik katsayıları ile belirlenmiş çelik hasırın güvenlik zarflardır.)

Tablo 4. Zayıf kaliteli kaya kütlesi için sayısal analizlerden elde edilen $T_{p l}$ ve $U_{t}$ değerleri

\begin{tabular}{|c|c|c|c|c|c|c|c|c|c|c|c|c|}
\hline \multirow{3}{*}{$\begin{array}{l}\text { ZAYIF } \\
\text { KAYA } \\
\begin{array}{c}\text { Derinlik } \\
(\mathrm{m})\end{array}\end{array}$} & \multicolumn{4}{|c|}{ Desteksiz } & \multicolumn{4}{|c|}{$\begin{array}{c}30 \mathrm{MPa} \text { dayanımlı püskürtme beton } \\
\text { için }\end{array}$} & \multicolumn{4}{|c|}{$\begin{array}{c}40 \mathrm{MPa} \text { dayanımlı püskürtme beton } \\
\text { için }\end{array}$} \\
\hline & \multicolumn{2}{|c|}{ Tavan } & \multicolumn{2}{|c|}{ Duvar } & \multicolumn{2}{|c|}{ Tavan } & \multicolumn{2}{|c|}{ Duvar } & \multicolumn{2}{|c|}{ Tavan } & \multicolumn{2}{|c|}{ Duvar } \\
\hline & $\begin{array}{l}\mathrm{T}_{\mathrm{pl}} \\
(\mathrm{m}) \\
\end{array}$ & $\mathrm{U}_{\mathrm{t}}(\mathrm{m})$ & $\mathrm{T}_{\mathrm{pl}}(\mathrm{m})$ & $\mathrm{U}_{\mathrm{t}}(\mathrm{m})$ & $\begin{array}{l}\mathrm{T}_{\mathrm{pl}} \\
(\mathrm{m})\end{array}$ & $\mathrm{U}_{\mathrm{t}}(\mathrm{m})$ & $\begin{array}{l}\mathrm{T}_{\mathrm{pl}} \\
(\mathrm{m})\end{array}$ & $\mathrm{U}_{\mathrm{t}}(\mathrm{m})$ & $\begin{array}{l}\mathrm{T}_{\mathrm{pl}} \\
(\mathrm{m})\end{array}$ & $\mathrm{U}_{\mathrm{t}}(\mathrm{m})$ & $\begin{array}{l}\mathrm{T}_{\mathrm{pl}} \\
(\mathrm{m})\end{array}$ & $\mathrm{U}_{\mathrm{t}}(\mathrm{m})$ \\
\hline 10 & 1.92 & 0.00078 & 1.565 & 0.000975 & 0 & 0.0007 & 1.375 & 0.000975 & 0 & 0.00063 & 1.34 & 0.000975 \\
\hline 50 & 2.31 & 0.00135 & 1.81 & 0.00165 & 0 & 0.0012 & 1.71 & 0.0015 & 0 & 0.00105 & 2.37 & 0.0015 \\
\hline 100 & 3.48 & 0.0035 & 3.36 & 0.00375 & 1.51 & 0.0024 & 2.67 & 0.0036 & 1.41 & 0.002 & 2.61 & 0.0036 \\
\hline 150 & 6.05 & 0.0068 & 3.84 & 0.0068 & 2.99 & 0.004 & 2.82 & 0.0064 & 2.28 & 0.0032 & 2.61 & 0.0064 \\
\hline 200 & 6.22 & 0.0105 & 3.43 & 0.0105 & 3.08 & 0.0054 & 2.54 & 0.0081 & 2.85 & 0.0045 & 2.54 & 0.0081 \\
\hline 250 & 7.78 & 0.0135 & 3.61 & 0.0135 & 5.73 & 0.009 & 2.58 & 0.0105 & 2.99 & 0.006 & 2.37 & 0.009 \\
\hline 300 & 7.81 & 0.016 & 3.65 & 0.016 & 6.85 & 0.012 & 2.61 & 0.014 & 4.75 & 0.01 & 2.59 & 0.012 \\
\hline 350 & 7.85 & 0.02 & 4.1 & 0.02 & 7.05 & 0.014 & 2.68 & 0.016 & 6.92 & 0.015 & 2.64 & 0.0175 \\
\hline 400 & 8.67 & 0.024 & 4.58 & 0.024 & 8.67 & 0.021 & 2.78 & 0.021 & 8.51 & 0.018 & 2.64 & 0.021 \\
\hline 450 & 9.64 & 0.03 & 3.78 & 0.027 & 9.64 & 0.0245 & 2.78 & 0.0245 & 8.76 & 0.021 & 2.64 & 0.024 \\
\hline
\end{tabular}


Tablo 5. Orta kaliteli kaya kütlesi için sayısal analizlerden elde edilen $T_{p l}$ ve $U_{t}$ değerleri

\begin{tabular}{|c|c|c|c|c|c|c|c|c|c|c|c|c|}
\hline \multirow{3}{*}{$\begin{array}{c}\text { ORTA } \\
\text { KAYA } \\
\begin{array}{c}\text { Derinlik } \\
(\mathrm{m})\end{array}\end{array}$} & \multicolumn{4}{|c|}{ Desteksiz } & \multicolumn{4}{|c|}{$\begin{array}{l}30 \mathrm{MPa} \text { dayanımlı püskürtme beton } \\
\text { için }\end{array}$} & \multicolumn{4}{|c|}{$40 \mathrm{MPa}$ dayanımlı püskürtme beton için } \\
\hline & \multicolumn{2}{|c|}{ Tavan } & \multicolumn{2}{|c|}{ Duvar } & \multicolumn{2}{|c|}{ Tavan } & \multicolumn{2}{|c|}{ Duvar } & \multicolumn{2}{|c|}{ Tavan } & \multicolumn{2}{|c|}{ Duvar } \\
\hline & $\begin{array}{l}\mathrm{T}_{\mathrm{pl}} \\
(\mathrm{m})\end{array}$ & $\mathrm{U}_{\mathrm{t}}(\mathrm{m})$ & $\begin{array}{l}\mathrm{T}_{\mathrm{pl}} \\
(\mathrm{m})\end{array}$ & $\mathrm{U}_{\mathrm{t}}(\mathrm{m})$ & $\begin{array}{l}\mathrm{T}_{\mathrm{pl}} \\
(\mathrm{m})\end{array}$ & $\mathrm{U}_{\mathrm{t}}(\mathrm{m})$ & $\begin{array}{l}\mathrm{T}_{\mathrm{pl}} \\
(\mathrm{m})\end{array}$ & $\mathrm{U}_{\mathrm{t}}(\mathrm{m})$ & $\begin{array}{c}\mathrm{T}_{\mathrm{pl}} \\
(\mathrm{m})\end{array}$ & $\mathrm{U}_{\mathrm{t}}(\mathrm{m})$ & $\begin{array}{l}\mathrm{T}_{\mathrm{pl}} \\
(\mathrm{m})\end{array}$ & $\mathrm{U}_{\mathrm{t}}(\mathrm{m})$ \\
\hline 10 & 0 & 0.00044 & 0.76 & 0.00056 & 0 & 0.0004 & 0.39 & 0.00056 & 0 & 0.0004 & 0.36 & 0.00056 \\
\hline 50 & 0 & 0.000585 & 1.26 & 0.000675 & 0 & 0.00054 & 0.82 & 0.000675 & 0 & 0.000495 & 0.75 & 0.000675 \\
\hline 100 & 1.39 & 0.00124 & 1.37 & 0.00143 & 0 & 0.00108 & 2.15 & 0.00135 & 0 & 0.00099 & 2.15 & 0.00135 \\
\hline 150 & 3.47 & 0.00275 & 2.59 & 0.003 & 0 & 0.0018 & 2.21 & 0.0022 & 0 & 0.0016 & 2.21 & 0.0022 \\
\hline 200 & 2.71 & 0.003 & 2.15 & 0.0035 & 0.98 & 0.00225 & 2.28 & 0.00325 & 0.97 & 0.00225 & 2.28 & 0.00325 \\
\hline 250 & 4.23 & 0.0049 & 2.49 & 0.00525 & 1.24 & 0.003 & 2.47 & 0.0042 & 0.98 & 0.0027 & 2.33 & 0.0039 \\
\hline 300 & 4.29 & 0.00585 & 2.98 & 0.0063 & 2.71 & 0.004 & 2.49 & 0.0056 & 2.59 & 0.0036 & 2.41 & 0.0056 \\
\hline 350 & 5.56 & 0.0078 & 3.03 & 0.0078 & 2.96 & 0.005 & 2.55 & 0.007 & 2.79 & 0.0045 & 2.47 & 0.007 \\
\hline 400 & 5.79 & 0.00845 & 3.04 & 0.0091 & 3.41 & 0.006 & 2.81 & 0.0084 & 2.82 & 0.00495 & 2.53 & 0.0077 \\
\hline 450 & 5.13 & 0.0091 & 3.11 & 0.0098 & 3.16 & 0.0077 & 2.98 & 0.0098 & 2.89 & 0.0064 & 2.72 & 0.0096 \\
\hline
\end{tabular}

Tablo 6. İyi kaliteli kaya kütlesi için sayısal analizlerden elde edilen $T_{p l}$ ve $U_{t}$ değerleri

\begin{tabular}{|c|c|c|c|c|c|c|c|c|c|c|c|c|}
\hline \multirow{3}{*}{$\begin{array}{c}\text { IYİ } \\
\text { KAYA } \\
\begin{array}{c}\text { Derinlik } \\
(\mathrm{m})\end{array}\end{array}$} & \multicolumn{4}{|c|}{ Desteksiz } & \multicolumn{4}{|c|}{$30 \mathrm{MPa}$ dayanımlı püskürtme beton için } & \multicolumn{4}{|c|}{$\begin{array}{l}40 \mathrm{MPa} \text { dayanımlı püskürtme beton } \\
\text { için }\end{array}$} \\
\hline & \multicolumn{2}{|c|}{ Tavan } & \multicolumn{2}{|c|}{ Duvar } & \multicolumn{2}{|c|}{ Tavan } & \multicolumn{2}{|c|}{ Duvar } & \multicolumn{2}{|c|}{ Tavan } & \multicolumn{2}{|c|}{ Duvar } \\
\hline & $\begin{array}{l}\mathrm{T}_{\mathrm{pl}} \\
(\mathrm{m})\end{array}$ & $\mathrm{U}_{\mathrm{t}}(\mathrm{m})$ & $\begin{array}{l}\mathrm{T}_{\mathrm{pl}} \\
(\mathrm{m}) \\
\end{array}$ & $\mathrm{U}_{\mathrm{t}}(\mathrm{m})$ & $\begin{array}{l}\mathrm{T}_{\mathrm{pl}} \\
(\mathrm{m}) \\
\end{array}$ & $\mathrm{U}_{\mathrm{t}}(\mathrm{m})$ & $\begin{array}{l}\mathrm{T}_{\mathrm{pl}} \\
(\mathrm{m})\end{array}$ & $\mathrm{U}_{\mathrm{t}}(\mathrm{m})$ & $\begin{array}{l}\mathrm{T}_{\mathrm{pl}} \\
(\mathrm{m}) \\
\end{array}$ & $\mathrm{U}_{\mathrm{t}}(\mathrm{m})$ & $\begin{array}{l}\mathrm{T}_{\mathrm{pl}} \\
(\mathrm{m})\end{array}$ & $\mathrm{U}_{\mathrm{t}}(\mathrm{m})$ \\
\hline 10 & 0 & 0.00025 & 0 & 0.0003 & 0 & 0.00022 & 0 & 0.0003 & 0 & 0.0002 & 0 & 0.0003 \\
\hline 50 & 0 & 0.00025 & 0 & 0.0003 & 0 & 0.00024 & 0 & 0.0003 & 0 & 0.00022 & 0 & 0.0003 \\
\hline 100 & 0 & 0.000495 & 0 & 0.000585 & 0 & 0.00045 & 0 & 0.00059 & 0 & 0.00045 & 0 & 0.00059 \\
\hline 150 & 0 & 0.00078 & 1.05 & 0.00091 & 0 & 0.000715 & 1.05 & 0.00091 & 0 & 0.00065 & 1.05 & 0.00091 \\
\hline 200 & 0 & 0.00102 & 1.05 & 0.00119 & 0 & 0.000935 & 1.05 & 0.00119 & 0 & 0.000935 & 1.05 & 0.00119 \\
\hline 250 & 0 & 0.0012 & 1.16 & 0.0015 & 0 & 0.0012 & 1.16 & 0.0015 & 0 & 0.00105 & 1.16 & 0.0015 \\
\hline 300 & 0 & 0.0015 & 1.2 & 0.0018 & 0 & 0.00135 & 1.2 & 0.0018 & 0 & 0.00135 & 1.2 & 0.0018 \\
\hline 350 & 0 & 0.00165 & 2.3 & 0.0021 & 0 & 0.00165 & 2.3 & 0.0021 & 0 & 0.0015 & 2.3 & 0.0021 \\
\hline 400 & 1.39 & 0.00275 & 2.36 & 0.0033 & 0 & 0.002 & 2.36 & 0.0024 & 0 & 0.0018 & 2.3 & 0.0024 \\
\hline 450 & 2.18 & 0.003 & 2.36 & 0.004 & 1.42 & 0.0033 & 2.36 & 0.0044 & 0 & 0.0024 & 2.3 & 0.0039 \\
\hline 530 & & & & & & & & & 1.4 & 0.003 & 2.8 & 0.0039 \\
\hline
\end{tabular}

\section{Sonuçlar}

Püskürtme beton dayanımın derinlikle ilişkisini belirlemek amacıyla yapılan bu çalışmada, Zayıf, Orta ve İyi kaliteli kaya kütleleri seçilmiştir. Bu kaya sınıflarında sınıflarında püskürtme beton en etkili destek elemanı olmanıdır $\mathrm{RMR}_{89}$ için çok zayıf kaliteli kayalarda çelik iksa desteğinin ön planda olması ve çok sağlam kaliteli kayalarda ise püskürtme betonun desteklemekten ziyade emniyet için uygulanmasından dolayı bu iki sınıf göz ardı edilmiştir.

İyi kaliteli kaya kütleleri için yapılan analizlerde $30 \mathrm{MPa}$ dayanımlı püskürtme beton $480 \mathrm{~m}$ örtü kalınlığına kadar yenilmeden desteklemeye devam etmektedir. Püskürtme beton dayanımı $40 \mathrm{MPa}$ 'a çıkartıldığında $530 \mathrm{~m}$ örtü kalınlı̆̆ına kadar bu destek sistemi duraylı kalabilmektedir. İyi kaliteli kaya sınıfı için ise $530 \mathrm{~m}$ örtü kalınlığından sonra bir alt kaya kütle sinıfinın destek sistemini kullanmak yenilmelerin önüne geçmektedir. İyi kaliteli kaya için elde edilen diğer bir sonuç ise, püskürtme beton dayanımı $20 \mathrm{MPa}$ değerine düşürüldüğünde $410 \mathrm{~m}$ örtü kalınlığına kadar destek sisteminde yenilme olmamasidır.

Orta kaliteli kaya kütle sınıfı için yapılan analizlerde, $30 \mathrm{MPa}$ dayanımlı püskürtme betonda, $310 \mathrm{~m}$ örtü kalınlığına kadar yenilme olmamış, beton dayanımı 40 MPa'a çıkartıldığında ise $420 \mathrm{~m}$ örtü kalınlığına kadar yenilmeden kalabilmiştir. 

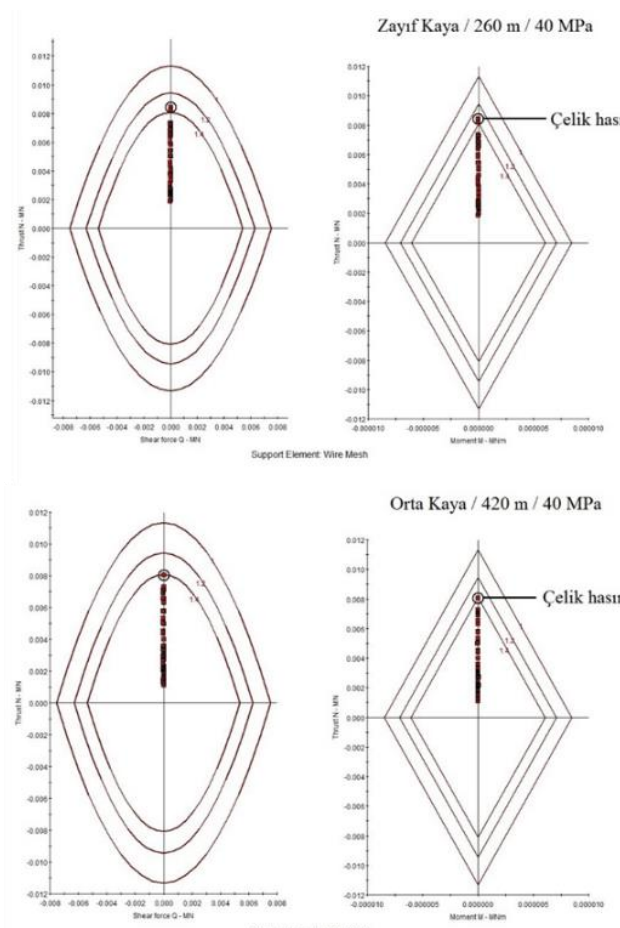

Orta Kaya / 420 m / 40 MPa
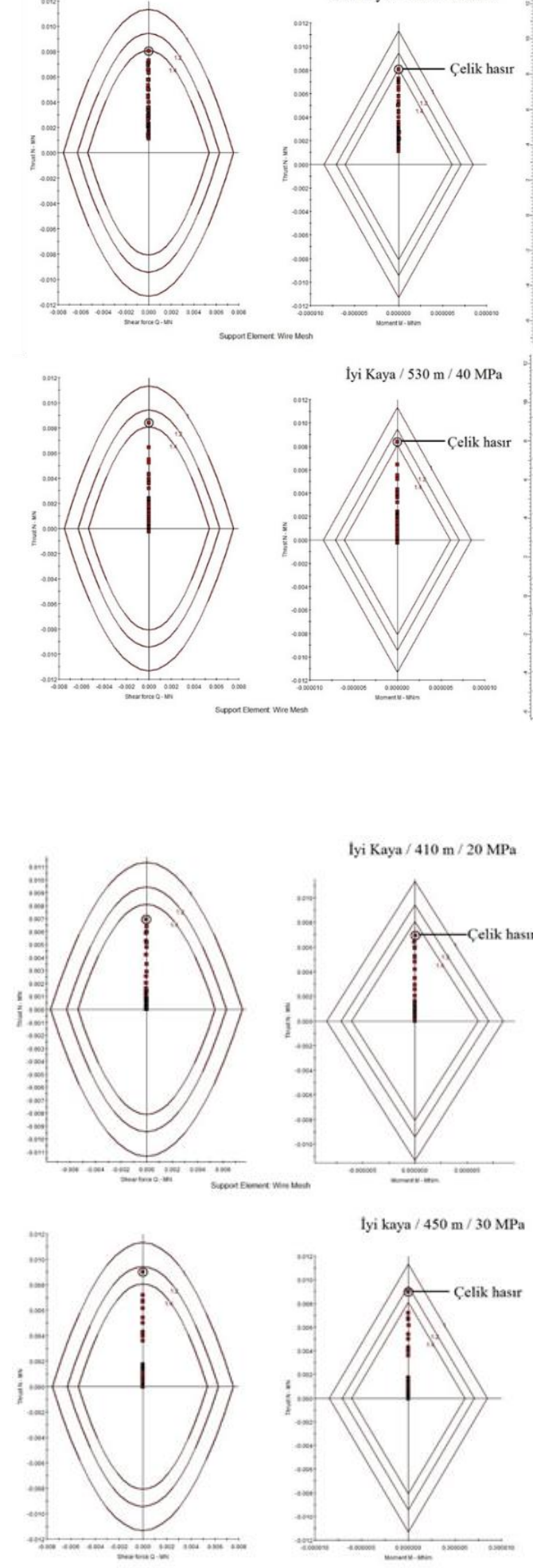
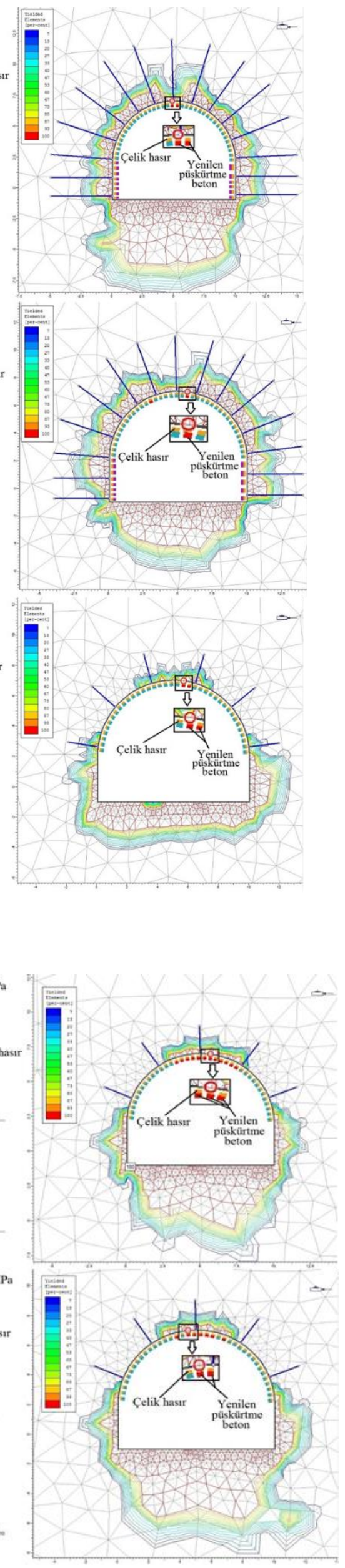

Șekil 3. $40 \quad$ MPa'llk püskürtme betonda çelik hasır destek kapasitesi grafikleri ve plastik zon yay1lımı (1-1.2-1.4, güvenlik katsayıları ile belirlenmiş çelik hasırın güvenlik zarflardır).

Şekil 4. 20 MPa' lik püskürtme betonda Çelik hasır destek kapasitesi grafikleri ve plastik zon yayllimi (1-1.2-1.4, güvenlik katsayıları ile belirlenmiş çelik hasırın güvenlik zarflardır). 
Tablo 7. İyi kaliteli kaya sınıfında $20 \mathrm{MPa}$ dayanımlı püskürtme betonun uygulanması durumunda sayısal analizlerden elde edilen $\mathrm{T}_{\mathrm{pl}}$ ve $\mathrm{U}_{\mathrm{t}}$ değerleri.

\begin{tabular}{ccccc}
\hline $\begin{array}{c}\text { RMR }(\mathrm{Good}) \\
20 \mathrm{MPa}\end{array}$ & \multicolumn{2}{c}{ Tavan } & \multicolumn{2}{c}{ Duvar } \\
\hline Derinlik $(\mathrm{m})$ & $\mathrm{T}_{\mathrm{pl}}(\mathrm{m})$ & $\mathrm{U}_{\mathrm{t}}(\mathrm{m})$ & $\mathrm{T}_{\mathrm{pl}}(\mathrm{m})$ & $\mathrm{U}_{\mathrm{t}}(\mathrm{m})$ \\
\hline $10 \mathrm{~m}$ & 0 & 0.00022 & 0 & 0.00028 \\
$50 \mathrm{~m}$ & 0 & 0.00024 & 0 & 0.0003 \\
$100 \mathrm{~m}$ & 0 & 0.000495 & 0 & 0.000585 \\
$150 \mathrm{~m}$ & 0 & 0.000715 & 1.05 & 0.00091 \\
$200 \mathrm{~m}$ & 0 & 0.000935 & 1.05 & 0.00119 \\
$250 \mathrm{~m}$ & 0 & 0.0012 & 1.16 & 0.0015 \\
$300 \mathrm{~m}$ & 0 & 0.00135 & 1.2 & 0.0018 \\
$350 \mathrm{~m}$ & 0 & 0.00165 & 2.3 & 0.0021 \\
$400 \mathrm{~m}$ & 0 & 0.002 & 2.36 & 0.0024 \\
$410 \mathrm{~m}$ & 1.52 & 0.0033 & 2.5 & 0.0044 \\
\hline
\end{tabular}

Analizlerden elde edilen diğer bir sonuç ise $420 \mathrm{~m}$ örtü kalınlığından sonra beton dayanımını artırmak yerine kaya sinıfi bir derece daha düşürmek tünelin duraylılığı için yeterli olmaktadir.

$\mathrm{Bu}$ çalışma kapsamında yapılan analizlere göre, zayıf kaliteli kaya kütlelerine $\mathrm{RMR}_{89}$ destek sistemi $30 \mathrm{MPa}$ 'lı püskürtme beton dayanımı ile uygulandığında püskürtme betonda yenilmeler $200 \mathrm{~m}$ örtü kalınlığında başlarken, püskürtme beton dayanımı 40 MPa'a çıkartıldığında püskürtme beton $260 \mathrm{~m}$ örtü kalınlığında yenilmeye başlamıştır. Ayrıca, beton kalınlığını arttırmanın da bir çözüm olabileceği düşünülebilir ancak bu durumda yeni bir destek sistemi önerilmiş olacağından betonun yenildiği derinliklerin belirlenip beton dayanımını arttırma yolu seçilmiştir.

$\mathrm{Bu}$ çalışmadan elde edilen sonuçlar, kazı derinliğinin artması ile birlikte, uygulanan destek sistemlerinin gözden geçirilmesi, destek elemanlarının dayanımlarının artırılması veya bir alt kaya sınıfına ait desteklerin kullanılması gerektiğini göstermektedir.

\section{Kaynaklar}

Badr, A, 2016. Statistical Analysis of the Variability in Shotcrete Strength, Global Journal of Researches in Engineering: $\mathrm{E}$ Civil And Structural Engineering, Volume 16 , Issue 4.
Badr, A., ve Brooks, J.J., 2008. "Rebound and Composition of in-Situ Polypropylene Fibre-Reinforced Shotcrete," 11th 6 Intl Conf Durability of Building Materials \& Components, 11DBMC, Istanbul, Turkey, 11-14 May, Vol. 1, pp. 569-576.

Barton, N.R., Lien, R., and Lunde, J., 1974. Engineering classification of rock masses for the design of tunnel support, Rock Mechanics, v. 6, p. 189-239.

Barros, J.A., Lourenço, L.A., Soltanzadeh, F. And Taheri, M. (2014) "Steel-fibre reinforced concrete for elements failing in bending and in shear," European Journal of Environmental and Civil Engineering, 31 18(1), pp.33-65.

Beauprè, D., Dufour,J.F., Hutter, J. ve Jolin, M., 2005. Variability of compressive Strength of Shotcrete in a Tunnel-Lining Project, Shotcrete, V. 5, No. 2, pp.22-25.

Bieniawski, Z.T., 1973, Engineering classification of jointed rock masses: Transaction of the South African Institution of Civil Engineers, v. 15, p. 335-344.

Bieniawski, Z.T., 1989. Engineering Rock Mass Classifications. Wiley, 251pp, New York.

Bieniawski, Z.T., 1993, Classification of rock masses for engineering: The RMR system and future trends, In:Hudson, J.A., ed., Comprehensive Rock Engineering, Volume 3: Oxford, Pergamon Press, p. 553-573, New York. 
Cai, M., Kaiser, P.K., Tasaka, Y. and Minami, M., 2007. Determination of residual strength parameters of jointed rock masses using the GSI system, International Journal of Rock Mechanics and Mining Sciences, 4 (2), 247-265.

Celada, B., Tardaguila, I., Varona, P., Rodriguez, A. and Bieniawski, Z.T., 2014. Innovating tunnel design by an improved experiencebased RMR system. In: World Tunnel Congress, May 9th to 15th 2014, Iguassu Falls, Brazil.

Deere, D.U., 1964. Technical description of rock cores for engineering purposes, Rock Mech. Rock Eng. 1, 17-22.

Fenner, R., 1938. Untersuchungen zur Erkenntnis des Gebirgsdrucks, Glückauf, 74, 32, 681695.

Genis, M., Basarir, H., Ozarslan, A., Bilir, E. and Balaban, E., 2007. Engineering geological appraisal of the rock masses and preliminary support design, Dorukhan Tunnel, Zonguldak, Turkey. Engineering Geology, 92, 14-26.

Gurocak, Z., Solanki, P. and Zaman, M.M., 2007. Empirical and numerical analyses of support requirements for a diversion tunnel at the Boztepe dam site, eastern Turkey. Engineering Geology. 91, 194-208.

Gurocak, Z., 2011. Analyses of stability and support design for a diversion tunnel at the Kapikaya dam site, Turkey, Bulletin of Engineering Geology and the Environment, 70, 41-52.

Hoek, E., Kaiser, P.K. ve Bawden, W.H., 1995. Support of Underground Excavations in Hard Rock. Rotterdam, Balkema

Hoek, E., 2007, Practical rock engineering, RocScience.

ISRM, (International Society for Rock Mechanics), 1981. ISRM Suggested Methods: Rock Characterization, Testing and Monitoring, Pergamon Press, London, $211 \mathrm{~s}$.

Kaya, A., Bulut, F., Alemdag, S., ve Sayın, A. (2011). Analysis of support requirements for a tunnel portal in weak rock: A case study in Turkey. Scientific Research and Essays, 6(31), 6566-6583.
Kaya, A. ve Bulut, F. (2013). Stability analyses of tunnels excavated in weak rock masses using empirical and numerical methods, Jeoloji Mühendisliği Dergisi, 37(2), 103116.

Kaya, A., and Sayın, A. (2017) Engineering geological appraisal and preliminary support design for the Salarha Tunnel, Northeast Turkey. Bull Eng Geol Environ, DOI: $10.1007 / \mathrm{s} 10064-017-1177-2$

Kanik, M., Gurocak, Z. and Alemdag, S., 2015. A comparison of support systems obtained from the RMR89 and RMR14 by numerical analyses: Macka Tunnel project, NE Turkey, Journal of African Earth Sciences, Volume 109, September 2015, 224-238.

Kirsten, 1992. Comparative efficiency and ultimate strength of mesh- and fibre reinforced shotcrete as determined from full-scale bending tests, Journal of the South African Institute of Mining and Metallurgy, Nov., 303-322.

KGM (Karayolları Genel Müdürlüğü), 2013. NATM Uygulamalı Yeraltı Tünel İşleri Teknik Şartnamesi, Karayolları Genel Müdürlüğü, Ankara.

Lauffer, H., 1958, Gebirgsklassifizierung für den Stollenbau: Geology Bauwesen, v. 24, p. 46-51.

Mohajerani, A., Rodrigues, D., Ricciuti,C., ve Wilson, C., 2015. Early-Age Strength Measurement of Shotcrete, Journal of Materials, Vol 2015, pp 1-10.

NIOSH, 2014. Shotcrete design and installation compliance testing: early strength, load capacity, toughness, adhesion strength, and applied quality," Martin et al. edit, National Institute for Occupational Safety and Health, Publication No. 2015-107, RI 9697.

Palmström, A., 1995. RMi-a rock mass characterization system for rock engineering purposes. Ph.D. thesis, Univ. Of Oslo, Norway, 400 pp

Patel, P.A., Desai, A.K., ve Desai, K.A., 2012. Evaluation of engineering properties for polypropylene fiber reinforced concrete, International Journal of Advanced Engineering Technology, 3(1), pp.42-45. 
Rocscience, 2006. Roclab bilgisayar program1, www.rocscience.com

Rocscience Inc, 2011. Phase ${ }^{2}$ v8.0 Finite Element Analysis for Excavations and Slopes, Rocscience Inc., Toronto, Ontario, Canada.

Sheorey, P.R., Murali, M.G., Sinha, A., 2001. Influence of elastic constants on the horizontal in situ stress. Int. J. Rock Mech. Min.Sci. 38 (1), pp 1211-1216.

Stini, I., "Tunnelbaugeologie," Springer-Verlaa, Vienna, 1950, p 336.

Terzaghi, K., 1946, Rock defects and loads on tunnel supports, in Proctor, R.V., and White, T.L., eds., Rock tunneling with steel support, Volume 1: Youngstown,Ohio, Commercial Shearing and Stamping Company p. 17-99.

Wickham, G.E., Tiedemann, H. R. and Skinner, E. H., 1972, Support determination based on geologic predictions, In: Lane, K.S.a.G., L. A., ed., North American Rapid Excavation and Tunneling Conference: Chicago, New York: Society of Mining Engineers of the American Institute of Mining, Metallurgical and Petroleum Engineers, p. 43-64.

Wood, D.F., Banthia, N. ve Trottier, J-F, 1993. A comparative study of different steel fibres in shotcrete. In Shotcrete for underground support VI, Niagara Falls, 57- 66. New York: Am. Soc. Civ. Engrs

Yalcin, E., Gurocak, Z., Ghabchi, R. ve Zaman, M, 2016. Numerical Analysis for a Realistic Support Design: Case Study of the Komurhan Tunnel in Eastern Turkey, International Journal of Geomechanics, Vol 16(3)

Zhang, L. 2014, Variability of Compressive Strength of Shotcrete in a Tunnel-Lining Project. www.shotcrete.org 